to predict the life under the stress conditions found in service. The variation from cast to cast within a particular specification is under investigation.

There are a further fifty dual-purpose creep/rupture units which can be used either as specimen rupture machines or as creep machines using dial gauge extensometers where less-accurate creep measurement is required. They are at present employed in measure. ments on turbine casings. One large machine with 15-ton loading has been installed for rupture-testing of full sections of steampipe.

The temperatures of the specimens are maintained by electric furnaces, the range of temperature of which at present extends from $450^{\circ} \mathrm{C}$. to $700^{\circ} \mathrm{C}$., but can be raised above this temperature when future requirements demand. The furnace temperature is maintained automatically by an electronic controller, to within $\pm 3^{\circ} \mathrm{C}$. up to $600^{\circ} \mathrm{C}$. and to within $\pm 4^{\circ} \mathrm{C}$. above $600^{\circ} \mathrm{C}$. Temperatures of the specimens themselves are measured by means of thermocouples (of which there are three on each specimen) in the high-sensitivity units. The thermocouple readings can be channelled selectively to a central control desk for manual measurement, but during critical periods they can be connected to one of 36 continuous record- ing charts situated in the Laboratory. In the rupture units there are five thermocouples distributed among the ten specimens. These, too, can be channelled to the control desk.

Another important project which is being undertaken in the new Laboratory is the testing to destruction of thick-walled tubes by applying steam pressure for long periods of time at temperatures encountered in service. This enables the creep data obtained in the Laboratory to be correlated with data on actual tubes so that the expected life in practice can be assessed. In testing creep in the Laboratory only a single uni-axial stress is applied whereas a steampipe is subjected to a complex stress system. Four such test rigs have been operating in the Electrical Research Association during the past three years. There are now fifteen rigs.

The data obtained in the new Laboratory will be subject to constant scrutiny as a means of providing more understanding of the mechanism of creep resistance of high-temperature steels. Knowledge of this kind will almost certainly be of benefit in the future development of steels for still higher temperatures, the demand for which is likely to continue for a long time.

\title{
CLIMATOLOGY AND CONSERVATION IN MUSEUMS
}

$\mathrm{T}$ HE Commission for Museum Laboratories of the International Council of Museums and the International Study Centre for the Preservation and Restoration of Cultural Property have recently undertaken a world-wide inquiry into the subject of environment in relation to conservation. Replies from sixty-four institutions to a questionnaire on the subject, and further study of the situation thus revealed, form the basis of a 46-page report*. In it, museum curators, rather than scientists specializing in conservation, are provided with a useful compendium on the atmosphere and its contaminants, hygrometry, instrumentation and equipment for the control of museum climate. In addition there are several useful reference tables relating to conditions within and outside museums in various parts of the world.

As is proper for documents issued by an international organization, several authors from various European countries have contributed, but the actual publication consists of complete texts in French and in English. Taking into account the polyglot sources of the material, the effort can only be said to have been altogether praiseworthy. Moreover, the fact that the report is written for curators who must be assumed to have little knowledge of the physics involved, must have added to the task. Faced with this require. ment, however, it is unfortunately all too easy to stray away from rigorous scientific exposition for the sake of a tempting analogy. For example, it may be acceptable in the introductory paragraph to compare inanimate objects with human beings in their reaction to the environment: "They live and breathe in the sense that there is continual if imperceptible change arising from their adaptation to the

* International Centre for the Study of the Preservation and the Restoration of Cultural Property, Rome. Works and Publication III: Climatology and Conservation in Museums. (Reprinted from Museum, 13, No. 4, 1960.) Pp. 201-289. (Rome: International Cultural Property, Vla Cavour, 266, 1960. Also available at H.M.S.O.) ambient conditions of the museum"; but, is it wise to persist with: "Some objects have a surprising capacity for adapting themselves to environment apparently without deleterious effect. Thus, a particular piece of wood or bronze may be recovered in remarkable condition after having been conserved for centuries in a swamp or bog; or a certain picture which has been exposed in a damp church may survive the ill-effects beyond all expectation. Let them be brought from their accustomed habitat into a museum, however, and the true state of affairs will soon be manifest, even where the atmosphere is rigorously conditioned"? (p. 243). Again: "The crux of the matter is to be found in the past history of the specimen, its structure and the conditions to which it has already become acclimatised. As is well known. even the best museum conditions can be dangerous for a painted panel that has been normally housed in a cold, damp country house" (p. 253). This may or may not be a phenomenon which is observable under scientific control, but if it is, to imply a conditioning process in the biological sense only helps to perpetuate the notion which is sometimes present among curators that objects, particularly paintings, lose their 'resistance' in the soft environment of the airconditioned gallery and decay, or alternatively, become unfit to withstand uncontrolled conditions.

Where the equilibrium that the object will attain in the museum results in a considerable change in moisture content, there will obviously be undesirable - often catastrophic-volume changes. Special techniques have been developed for dealing with such cases as, for example, water-logged wood. But it is difficult at first to entertain the idea that stabilizing the atmosphere at parameters well within those of the natural cycles can be harmful. Evidence on the alleged phenomenon is unfortunately biased for the simple reason that objects are closely and regularly inspected, once they have entered the museum-but 
not before. Even so it is not without interest to proceed on hypothetical lines because it is the experience of every curator that certain objects prove intractable. It might be supposed, for example, that continual swelling and shrinking prevents embrittlement in organic materials. Another possibility is connected, not unreasonably, with gradients in moisture content within the object. Certain forms of deterioration in paintings (both panel and canvas) can be shown undoubtedly to result from the gradient set up when the back is in close proximity to what may be a cool and/or damp wall, while the front enjoys constant and ideal but different conditions. It cannot be assumed that such steady-state conditions are a priori more favourable on all counts than cyclic ones in which even a reversal of the gradient is possible. The transfer of soluble material, whether salts or adhesives, within the object is a souree of breakdown, particularly at an interface where the structure is laminar. The report does not deal with this phenomenon beyond pointing out that the varia. tion in climate within a room may be such as to produce a 12 per cent variation in relative humidity over $3 \mathrm{~m}$. in height. The importance of moisture content gradients relative to the main hazard-the swelling and shrinking of hydrophilic gels-is a matter for investigation. The result may well explain the unexpected results of air-conditioning which sometimes disappoint the curator. In so many investigations connected with conservation the actual number of variables is difficult to define, and generalizations are often misleading. A case in point is the assumption (p. 247) that picture canvases become slack when the atmosphere is over-dry, as raw natural fibre textiles do. The converse is more often observed because the textile behaviour is opposed by that of the animal glue with which it is impregnated-old masters made use of this effect to tension their canvases.

The report is generously illustrated with diagrams, photographs of instruments and conditioning apparatus, and with striking examples of objects which have suffered deterioration due to unfavourable environment.
S. REeS Jones

\section{VIEWING AND LISTENING}

A YEAR ago the British Broadcasting Corporation published a report of an audience research inquiry under the title The Public and the Programmes. The interest which this aroused has encouraged the Corporation to make available other findings of its Audience Research Department. Facts and Figures about Viewing and Listening* offers, in a series of twelve charts, some facts which are important to a proper understanding of what has been happening to viewing and listening habits in recent years.

Each chart has its accompanying commentary explaining the significance of the matter dealt with and directing attention to outstanding points.

Charts I and II show the extent to which the British public uses the three broadcasting services, BBC Sound, BBC-TV and ITV. This is assessed in two ways-in terms of the numbers who typically listen (or view) in the course of a single day (that is, the numbers of 'patrons'), and in terms of the average number who are listening (or viewing) at any given moment (that is, the 'average audience').

Chart I, "The Patronage of Broadcasting", shows the number of adult 'patrons' for each service quarter by quarter for the past three years and shows that the number of adult patrons of BBC Sound has not fluctuated very greatly (this, despite the continuing increase in television coverage). The numbers of adult patrons of both BBC-TV and ITV have shown a rising tendency, with a seasonal fluctuation. The number of BBC-TV adult patrons is consistently above that of ITV because, if for no other reason, though all viewers can see BBC-TV, some cannot vet receive ITV.

The curves for child-patrons show that a much smaller proportion of children than adults patronize Sound and a larger proportion of children patronize ITV than patronize BBC-TV.

In Chart II a different picture emerges when the services are compared in terms of 'average audience' than when they are compared in terms of 'patrons'.

* British Broadcasting Corporation. Facts and Figures about Viewing and Listening. In Twelve Charts with a Commentary. Pp.
Thus, Sound's patrons exceed those of either television service, but its average audience is much smaller than that of BBC-TV or ITV. The explanation lies in the fact that the average patron of sound listens for a relatively small proportion of the time during which sound broadcasting is transmitted. Similarly, though there are more patrons of BBC-TV than of ITV, the former spend less time viewing ( $1 \mathrm{hr} .44$ min. a day) than do the latter ( $2 \mathrm{hr} .12 \mathrm{~min}$.); hence the number who are viewing ITV at any given moment $(7,500,000)$ is greater than the number who are viewing $\mathrm{BBC}-\mathrm{TV}(6,350,000)$.

Chart III shows the relationship, since 1952-53, between the amount of time (in the evening) during which television programmes were broadcast and the amount of time which the average viewer actually spent in viewing. Two points emerge from this comparison: (1) that an increase in the number of television programme hours in the evening is not followed by a proportionate increase in viewing; (2) that, since commercial television became available, there has been little difference between the amount of time spent in evening viewing by those who could receive both $\mathrm{BBC}$ and ITV and by those who could only receive BBC-TV.

These results suggest that the introduction of further television services (a third and perhaps a fourth) will be unlikely to cause an increase in the total amount of time which people devote to viewing.

Charts IV and V illustrate the way in which people with multichannel receivers distribute their viewing between BBC-TV and commercial television. Chart IV shows the proportions which, on the average day in each quarter of the past two years, confined their viewing to BBC-TV, viewed both BBC and ITV, confined the viewing to ITV, or did not view at all. The last of these categories tends to vary seasonally, being greatest in the July-September quarter. Apart from this, there has been a tendency in the past two years for fewer adults to confine their viewing to ITV and for considerably more to view both services. Among children, many more restrict their viewing to ITV than restrict it to BBC-TV. 